Rainer Stollmann • Groteske Aufklärung 


\section{Rainer Stollmann}

\section{Groteske Aufklärung}

Studien zu Natur und Kultur des Lachens 
Die Deutsche Bibliothek - CIP-Einheitsaufnahme

Stollmann, Rainer:

Groteske Aufklärung : Studien zu Natur und Kultur des Lachens / Rainer Stollmann.

- Stuttgart : M und P, Verl. für Wiss. und Forschung, 1997

ISBN 978-3-476-45180-4

\author{
ISBN 978-3-476-45180-4 \\ ISBN 978-3-476-04275-0 (eBook) \\ DOI 10.1007/978-3-476-04275-0
}

Dieses Werk ist einschließlich aller seiner Teile geschützt. Jede Verwertung außerhalb der engen Grenzen des Urheberrrechtsgesetzes ist ohne Zustimmung des Verlages unzulässig und strafbar. Das gilt insbesondere für die Vervielfältigungen, Ühersetzung, Mikroverfilmungen und Einspeicherung in elektronischen Systemen.

M \& P Verlag für Wissenschaft und Forschung ein Verlag der J.B. Metzlerschen Verlagsbuchhandlung und Carl Ernst Poeschel Verlag GmbH in Stuttgart

(C) 1997 Springer-Verlag GmbH Deutschland Ursprünglich erschienen bei J.B. Metzlersche Verlagsbuchhandlung und Carl Ernst Poeschel Verlag GmbH in Stuttgart 1997 


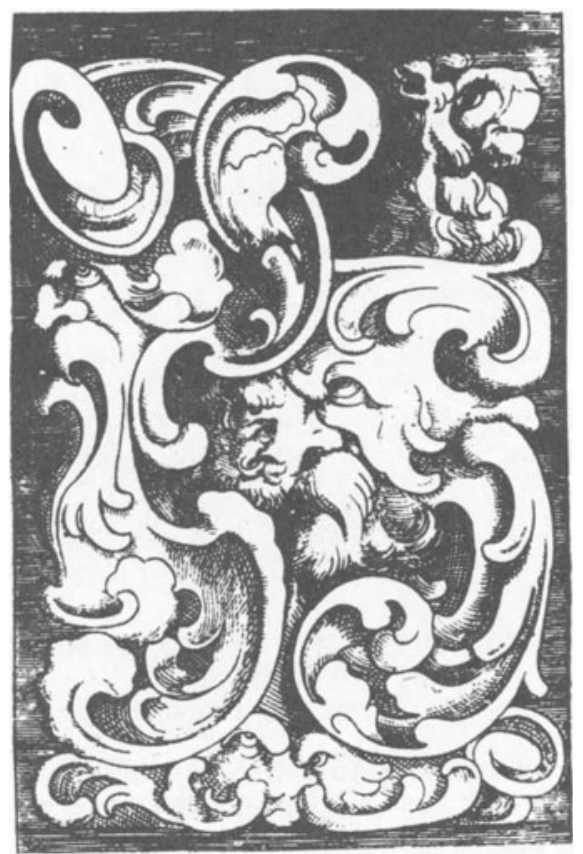

Es muß in allem, was ein lebhaft erschütterndes Lachen erregen soll, etwas Widersinniges sein (woran also der Verstand an sich kein Wohlgefallen finden kann).

I. Kant, "Kritik der Urteilskraft"

Man müßte eine Geschichte des Lachens schreiben.

A. Herzen

Wenn die Wahrheit ganz ernst auftritt, wird sie totgeschlagen.

A. Kluge, "Abschied von gestern" 


\section{INHALT}

\section{DIE NATUR DES LACHENS 7}

\section{Mythos, Märchen, Epos 7}

\section{Lachen im Blick der Naturwissenschaften 31}

Darwin 31 / Darwinisten 44 / Ist Lachen ein Reflex? Der elementare Zusammenhang: Lachen und Kitzeln 53 / Lachen als Grenzform des Spiels 68 / Ursprung des Lächelns 72 / Robert Musil: Kann ein Pferd lachen? 77

\section{ZUR GROTESKE IN DER RENAISSANCE 84}

Bachtin 84 / Öffentlichkeit und Lachen 91 / Rabelais 100 / Einige Bilder des grotesken Realismus 104

Das berühmteste Lächeln der Welt 113

Till Eulenspiegel, der bodenlose Bauer 129

Eulenpiegel in Bremen 129 / Volkskönig Leckarsch 139 / Chiffren historischer Erfahrung 142 / Ekel; groteske Aufklärung 163 / Die älteste Eulenspiegel-Geschichte: Der Bremer Bischof und die Töpferin 178 / Grobheit 194 / Das mündige Kind 203

\section{RENAISSANCE DER GROTESKE IM 20. JAHRHUNDERT 213}

Entwurf: Feudalismus der Dinge als Horizont der Groteske 213

Jaroslav Hašek: Der brave Soldat Schwejk 225

Der emanzipierte Hund 225 / Zynische Naivität 237 / Die groteske Unwirklichkeit des Faktischen 244 / Das bürgerliche Erbe 250 / Dummheit als List gegen die Dinge 256 / Notiz zu Brechts "Schweyk" 267

Das Diasporalachen Kafkas 269

Groteske Mikrostruktur der Sprache: "Der Bau" 273 / Das Verschwinden des Autors 281 / "Die Lärmtrompeten des Nichts": "Der Prozeß" 290 / Berührung zwischen Hašek und Kafka 306

Berlin Alexanderplatz - ein grotesker Roman 309

Der preußische "Ausgang aus Unmündigkeit" 313 / Ein Unfallmord 319/ Impotenz als Zeichen von Liebe, Vergewaltigung als Befreiung von Impotenz 329 / Unvermögen zur Trennung, Unfähigkeit der Bindung 339 / Der Karneval der Dinge 352 / Notiz zum "Schluß" 359 / "Die Ermordung einer Butterblume" 366 